Letter to the Editor

\title{
Extrapyramidal side-effects and clinical response during acute neuroleptic treatment of schizophrenia
}

\author{
F Benazzi* \\ Psychiatry Service, Public Hospital Morgagni, 47100 Forli, Italy
}

For most cases of acute schizophrenia, the optimal dose of haloperidol is around $10 \mathrm{mg} /$ day. Higher doses have been claimed to be no more effective and to cause more extrapyramidal side-effects (EPS) and more drop-outs. The relationship between improvement in positive symptoms and EPS is not clear (Levinson et al, 1990; Van Putten et al, 1990; Rifkin et al, 1991).

Twenty consecutive inpatients with acute schizophrenia (DSM III-R) were treated with neuroleptics and the relationship between improvement in positive symptoms and EPS was studied.

The study comprised 11 males and 9 females, mean (SD) age 33.2 (9.7) years, range 18-53 y. At baseline and weekly thereafter they were evaluated by the Brief psychiatric rating scale, BPRS (Overall and Gorham, 1962), the positive and negative syndrome scale, PANSS (Kay et al, 1989), and the Simpson-Angus scale for EPS (Simpson and Angus, 1970). Endpoint examinations were carried out at the end of the 4th week or before, if the patients were discharged. Most patients were taking oral neuroleptic medication when they relapsed and were hospitalized. In hospital, mean (SD) haloperidol equivalent dose was $10.9(4.7) \mathrm{mg} /$ day, range 5-20. The dose was adjusted according to clinical response. Haloperidol was the most widely used neuroleptic. Benzodiazepines were associated in $85 \%$ of cases, and anticholinergics prophylactically in $15 \%$.

A negative correlation $(r=-0.65, P<0.01)$ was found between endpoint percent improvement in positive symptoms and endpoint EPS severity.
The group was divided into two subgroups: those with less than $40 \%$ endpoint improvement in positive symptoms and those with $40 \%$ or greater improvement (table I).

Mean EPS severity in the less than $40 \%$ improvers was significantly higher than in the other subgroup.

There were no significant baseline differences in mean PANSS + score (positive symptoms), mean BPRS score, mean age and mean duration of treatment of current episode. Mean doses of neuroleptics and benzodiazepines were not significantly different.

The group was split into two endpoint subgroups, according to the presence or absence of akinesia (table II).

Endpoint mean percent improvement in positive symptoms was significantly higher in the akinesiasubgroup.

There were no significant baseline differences in mean PANSS + score, mean BPRS score, mean age and mean duration of treatment of current episode. Mean doses of neuroleptics and benzodiazepines were not significantly different.

The akinesia + subgroup did not have more dysphoria (a possible cause of reduced improvement). Different degrees of rigidity at endpoint were not associated with improvement in positive symptoms.

In conclusion, improvement in positive symptoms was associated with fewer EPS and lack of akinesia.

This study has several limitations, apart from the small sample size. It was an uncontrolled, non-blind

* Correspondence and reprints: via Pozzetto 17, 48010 Castiglione di Cervia RA, Italy 
Table I. EPS severity at endpoint according to different degrees of improvement in positive symptoms.

\begin{tabular}{lcc}
\hline & $\begin{array}{c}\text { Less 40\% } \\
(\mathrm{n}=12)\end{array}$ & $\begin{array}{c}40 \% \text { or greater } \\
(\mathrm{n}=8)\end{array}$ \\
\hline $\begin{array}{l}\text { Endpoint mean } \\
\text { Simpson score } \\
\text { (EPS severity) }\end{array}$ & 6.9 & $1.5 t=3.14, P<0.01$ \\
\hline
\end{tabular}

Table II. Improvement in positive symptoms according to the presence or absence of akinesia.

\begin{tabular}{lcc}
\hline & $\begin{array}{c}\text { Present } \\
(\mathrm{n}=9)\end{array}$ & $\begin{array}{c}\text { Akinesia } \\
\text { Absent } \\
(\mathrm{n}=11)\end{array}$ \\
\hline $\begin{array}{l}\text { Endpoint mean } \\
\text { percent improvement } \\
\text { in positive symptoms }\end{array}$ & 17.4 & $43.8 t=2.98, P<0.01$ \\
\hline
\end{tabular}

study, where doses were flexible and determined by clinical response. Several neuroleptics were used. In such a situation, patients who are less responsive tend to receive higher doses than patients who are highly responsive. Therefore, the negative correlation found between EPS and positive symptoms could be the result of partially refractory patients receiving higher doses and consequently developing more EPS. However, the mean dose of neuroleptics was not higher in the subgroup with less improvement than in the subgroup which improved substantially.

\section{References}

Kay SR, Opler LA, Lindenmayer JP (1989) The positive and negative syndrome scale (PANSS). Rationale and standardization. Br J Psychiatry 155 (suppl), 59-65

Levinson DF, Simpson GM, Singh H, Yadalam K, Jain A, Stephanos MJ, Silver P (1990) Fluphenazine dose, clinical response, and extrapyramidal symptoms during acute treatment. Arch Gen Psychiatry 47, 761-768

Overall JE, Gorham DP (1962) The brief psychiatric rating scale (BPRS). Psychol Rep 10, 799-812

Rifkin A, Doddi S, Karajgi B, Borenstein M, Wachspress M (1991) Dosage of haloperidol for schizophrenia. Arch Gen Psychiatry 48, 166-170

Simpson GM, Angus JWS (1970) A rating scale for extrapyramidal side-effects. Acta Psychiatr Scand 212, $11-19$

Van Putten T, Marder SR, Mintz J (1990) A controlled dose comparison of haloperidol in newly admitted schizophrenic patients. Arch Gen Psychiatry 47, 754-758 